\title{
Marian Ludgate-the scientist and her festschrift
}

\section{M. Dayan ${ }^{1} \cdot$ L. D. Premawardhana ${ }^{1}$}

Published online: 21 January 2020

(C) Springer Science+Business Media, LLC, part of Springer Nature 2020

Organising Marian Ludgate's festschrift was a joy. We already knew the spelling and the meaning of the word after John Lazarus's festschrift many years ago! Finding distinguished speakers was easy and they did not need much persuasion-Marian had been at the forefront of thyroid research, and colleagues were genuinely happy to talk about her contributions. Her friends and family, and former research fellows, collaborators and colleagues were keen to attend and honour this woman of science. It was therefore an organisers' dream. On the day, the event was very well attended and graced by many distinguished speakers who all had a close professional connection with Marian. John Lazarus and Colin Dayan chaired the two academic sessions with their usual skill and humour.

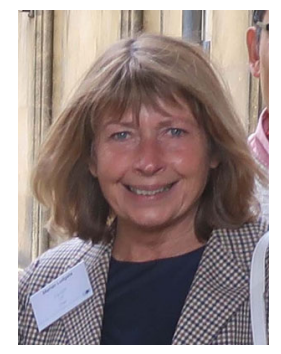

Professor Sir Dillwyn Williams spoke first on "Inherited Thyroid Tumours" and gave us an overview of thyroid cancer in familial adenomatous polyposis, and familial papilloid thyroid adenomas. Marian had been instrumental in describing the genetic basis of the latter. Professor Tony Weetman then gave us a masterclass on "Autoimmune Thyroid Disease" and the various stages of the history of our understanding of thyroid autoimmunity. One of Marian's earliest contributions was demonstrating disordered $\mathrm{T}$ cell regulation in Graves' disease (GD) and the immunomodulatory role of

L. D. Premawardhana

Premawardhanald@cardiff.ac.uk

1 Cardiff Thyroid Research Group, University Hospital of Wales, C2 Link, Cardiff CF14 4XN, UK thionamides-work done with Alan MacGregor. Professor Sabine Costagliola made an elegant presentation on "Thyroid Regeneration". Thereafter, Dr Wisia Furmaniak spoke about the "Practical Applications of Studies of The TSH Receptor". She introduced us to the emerging practical (and clinical) applications of the TSH receptor stimulating monoclonal antibody M22, and its inhibitory counterpart K1-70. Professor Dagmar Fuhrer-Sakel spoke on "Constitutive TSH Receptor Activation as a Hallmark of Thyroid Autonomy". She highlighted the importance of gain-of-function mutations of the TSH receptor resulting in its constitutive activation causing toxic adenoma and multinodular goitre, and hereditary nonautoimmune hyperthyroidism. The final presentation by Professor Anja Eckstein was on "Lessons From Mouse Models of Graves' Disease". She discussed experimental and clinical work on the immune mechanisms of GD and Graves' orbitopathy (GO), and the potential for modulating these both in animal models and human phase 1 studies.

There can be few in the area of thyroid research who do not know the name Marian Ludgate. For over 30 years, she has led advances in the field as the accompanying articles in the journal illustrate. A recurring theme of her work is to return to unresolved questions again and again until the true picture emerges.

Following her $\mathrm{PhD}, 2$ years of teaching in a school and starting her family, Marian was appointed as research assistant in Cardiff in 1982 where John Lazarus first introduced her to thyroid research. In 1986 she moved to the Institute of Interdisciplinary Research in Brussels, a relocation which confirmed her commitment to the thyroid, and was to prove a seminal influence on her future research. She worked with Professors Jacques Dumont and Gilbert Vassart, at a key time in the study of thyroid autoimmunity. Thyroglobulin had been identified as an autoantigen in 1956, but the nature of the remainder of the thyroid autoantigens was unclear. Marian was part of the team that used emerging techniques in molecular biology to clone and characterise first the Thyroid Peroxidase (previously known as the microsomal $[1,2])$ antigen and then, in a major coup, the TSH receptor (TSHr) - the key target in GD [3]. This 
allowed focussed study of stimulating autoantibodies in GD by functional expression of the receptor in laboratory cell lines, including the first reported recombinant bioassay [4]. Marian studied pathways of receptor activation and developed luminescent bioassays for TSHr stimulatory and blocking antibodies which were patented and used as the basis for commercial assays [5, 6].

Identifying the target autoantigen led Marian to replicate and extend these findings by creating an animal model. Along with Costagliola et al., she immunised mice with the recombinant $\mathrm{TSH}$ receptor and created the first animal model of GD [7, 8]. However, when she returned to Cardiff in 1994 after nearly 9 years in Brussels, she found it very difficult to replicate this model in Wales, and this became a "bete noire" for her until she finally unravelled the issues involved 20 years later. Undeterred, she widened her studies into naturally occurring mutations in the TSHr previously identified by the Brussels group along with Dagmar Fuhrer, including identifying an activating mutation in a large welsh kindred masquerading as GD [9]. In an elegant example of "reverse translation", she later used such an activating mutation to create an in vitro model of GO [10].

With the identification of the target autoantigen in GD, Marian's attention turned to the enigmatic link between thyroid overactivity and swelling in the retroorbital tissue seen in many but not all GD patients-GO. The simplest explanation was that the TSHr was also present in retroorbital tissue. Marian and colleagues in Cardiff had reported expression of the TSHr by Northern blot in adipose tissue in 1997 [11] and with Boschi, Daumerie and Many reported the expression of the TSHr protein in orbital tissues in 2005 [12]. This finding remained controversial as levels were low and the issue of the target antigen in GO was the subject of debate and editorials. However, Marian had also identified that the key cell in GO was not the extra-ocular muscle cells but the orbital pre-adipocyte. She, like all great scientists, followed the needs of the science rather than just using the techniques she was familiar with by developing expertise in adipocyte culture and biology. Together with Lei Zhang, they unravelled many of the signalling pathways by which TSHr activation leads to orbital adipogenesis (using activating TSHr mutations as an in vitro tool) and the remarkable ways in which orbital pre-adipocytes differ from standard white fat cells elsewhere in the body [13-15].

In the previous decade, John Lazarus had established the CATS study in Cardiff to explore the effects of thyroid hormone deficiency in pregnancy. With John's retirement and the lack of effect of thyroid supplementation during pregnancy on IQ at age 3, Marian recalled the children at age 7-10 for repeat assessment along with their mothersCATS II resulted. This demonstrated Marian's versatility in leading a very clinical rather than laboratory orientated study. Publications from the extensive data are still emerging.

Following the 2013 publication of Paul Banga's animal model of GD (and orbitopathy) and of other protocols for inducing thyrotoxicosis, Marian began to revisit her animal models but also used recent technology to study the gut microbiome to explain the environmental effects on the model, not least because of her frustrations in trying to replicate the original animal model back in Wales 20 years previously. She successfully led on and coordinated an EU FP7 bid (Germany, Italy UK) and "INDIGO" (Investigation of Novel biomarkers and Definition of the role of the microbiome in Graves Orbitopathy) was born. INDIGO has generated seminal findings including the robust replication of the animal model of GD and GO confirming that the key target of autoimmunity in the orbit is the TSHr as Marian had argued. The animal model has opened up many new avenues of study in GO and a new therapeutic optimism for this disfiguring condition. In addition, the emerging microbiome data and its regional variability and impact on the immune system represent a potential scientific explanation for Marian's “bete noire”. Although retired, Marian remains determined to complete the analysis of her data.

Marian has furthered the field of thyroidology in many other ways-serving on British and European Thyroid Association committees and the European Group of Graves Orbitopathy; as an Associate Editor of "Thyroid" and as a Senior Editor for the "Journal of Endocrinology" and the "European Journal of Endocrinology"; and a current editor for Frontiers in Endocrinology; as well as giving numerous invited lectures and international presentations. However, a major focus for her has always been "family"-not just her own immediate family and her grand-children (working less than full time since 2010 to accommodate their needs), but also her "scientific family", supervising more than $20 \mathrm{PhDs}$ and keeping in touch with and supporting the careers of her staff. All who have worked with her will remember the regular events she hosted at her home, but also her desire to be present at degree graduations and other key events to mark the progress of her trainees. Much of this commitment and the legacy it generates for future research can often go unnoticed, especially amongst those achieving this while working less than full time. I was therefore personally delighted when she was appointed as Professor in 2011, a richly deserved promotion. Although thyroid disease affects over a million people in the UK, it rarely attracts the attention of major funders that UK universities place emphasis on. But Marian has survived these and many other challenges. She has ensured that Cardiff has remained an international centre for thyroid research for over 30 years and has made advances in the field that will contribute to improved well-being for hundreds of thousands of people worldwide as well as ensuring that the study of thyroid 
disease has many well trained and committed scientists to continue the work.

\section{Compliance with ethical standards}

Conflict of interest The authors declare that they have no conflict of interest.

Publisher's note Springer Nature remains neutral with regard to jurisdictional claims in published maps and institutional affiliations.

\section{References}

1. F. Libert, J. Ruel, M. Ludgate, S. Swillens, N. Alexander, G. Vassart, C. Dinsart, Complete nucleotide-sequence of the human thyroperoxidase-microsomal antigen cDNA. Nucleic Acids Res. 15, 6735 (1987).

2. M. Ludgate, S. Mariotti, F. Libert, C. Dinsart, P. Piccolo, F. Santini, J. Ruf, A. Pinchera, G.Vassart. G, Antibodies to human thyroid peroxidase in autoimmune thyroid-disease-studies with a cloned recombinant complementary deoxyribonucleic-acid epitope. J. Clin. Endocrinol. Metab. 68, 1091-1096 (1989).

3. F. Libert, A. Lefort, C. Gerard, M. Parmentier, J. Perret, M. Ludgate, J.E. Dumont, G. Vassart, Cloning, sequencing and expression of the human thyrotropin (TSH) receptor-evidence for binding of autoantibodies. Biochem. Biophys. Res. Comm. 165, 1250-1255 (1989).

4. M. Ludgate, J. Perret, M. Parmentier, C. Gerard, F. Libert, J.E. Dumont, G. Vassart, Use of the recombinant human thyrotropin receptor (TSH-R) expressed in mammalian-cell lines to assay TSH-R autoantibodies. Mol. Cell. Endocrinol. 73, R13-R18 (1990).

5. J. VanSande, C. Lejeune, M. Ludgate, D.S. Munro, G. Vassart, J. E. Dumont, J. Mockel, Thyroid stimulating immunoglobulins, like thyrotropin activate both the cyclic-AMP and the PIP(2) Cascades in $\mathrm{CHO}$ cells expressing the TSH receptor. Mol. Cell. Endocrinol. 88, R1-R5 (1992).
6. N. Jordan, C. Rinderle, J. Ashfield, N. Morgenthaler, J. Lazarus, M. Ludgate, C. Evans, A luminescent bioassay for thyroid blocking antibodies. Clin. Endocrinol. 54, 355-364 (2001).

7. S. Costagliola, L. Alcalde, M. Tonacchera, J. Ruf, G. Vassart, M. Ludgate, Induction of thyrotropin receptor (TSH-R) autoantibodies and thyroiditis in mice immunized with the recombinant TSH-R. Biochem. Biophys. Res. Comm. 1994, 1027-1034 (1994).

8. S. Costagliola, P. Rodien, M.-C. Many, M. Ludgate, G. Vassart, Genetic immunization against the human thyrotropin receptor causes thyroiditis and allows production of monoclonal antibodies recognising the native receptor. J. Immunol. 160, 1458-1465 (1998).

9. D. Fuhrer, J. Warner, M. Sequeira, R. Paschke, J. Gregory, M. Ludgate, Novel TSHR germline mutation (met463val) masquerading as Graves' disease in a large welsh kindred with hyperthyroidism. Thyroid 10, 1035-1041 (2000).

10. L. Zhang, G. Baker, D. Janus, C. Paddon, D. Fuhrer, M. Ludgate, Biological effects of thyrotropin receptor activation on human orbital preadipocytes. Investig. Ophthalmol. Vis. Sci. 47, 5197-5203 (2006).

11. M. Crisp, C. Lane, M. Halliwell, D. Wynford-Thomas, M. Ludgate, Thyrotropin receptor transcripts in human adipose tissue. J. Clin. Endocrinol. Metab. 82, 2003-2005 (1997).

12. A. Boschi, C. Daumerie, M. Spiritus, C. Beguin, M. Senou, D. Yuksel, M. Duplicy, S. Costagliola, M. Ludgate, M.C. Many, Quantification of cells expressing the thyrotropin receptor in extraocular muscles in thyroid associated orbitopathy. Br. J. Ophthalmol. 89, 724-729 (2005).

13. Lei. Zhang, Timothy. Bowen, Fiona. Grennan-Jones, Carol. Paddon, Peter. Giles, Jason. Webber, Robert. Steadman, Marian. Ludgate, Thyrotropin receptor activation increases hyaluronan production in preadipocyte- fibroblasts-contributory role in hyaluronan accumulation in thyroid dysfunction. J. Biol. Chem. 284, 26447-26455 (2009).

14. Lei. Zhang, Fiona. Grennan-Jones, Carol. Lane, D.Aled. Rees, ColinM. Dayan, Marian. Ludgate, Adipose tissue depot specific differences in the regulation of hyaluronan production of relevance to Graves' orbitopathy. J. Clin. Endocrinol. Metab. 97, 653-662 (2012).

15. L. Zhang, F. Grennan-Jones, M.S. Draman, C. Lane, D. Morris, C. M. Dayan, A.R. Tee, M. Ludgate, Possible targets for nonimmunosuppressive therapy of Graves' orbitopathy. J. Clin. Endocrinol. Metab. 99, E1183-E1190 (2014). 